\title{
RELACIÓN ENTRE TIRSO DE MOLINA Y LOPE DE VEGA: APROXIMACIÓN A UN ESTADO DE LA CUESTIÓN ${ }^{1}$
}

\author{
Alejandro Loeza Zaldivar
}

Doi: https://doi.org/10.15517/rfl.v44i1.32856

URL: https://revistas.ucr.ac.cr/index.php/filyling

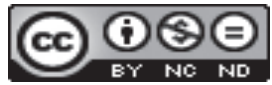

Esta obra está bajo una licencia Creative Commons

Reconocimiento-No Comercial-Sin Obra Derivada 



\title{
RELACIÓN ENTRE TIRSO DE MOLINA Y LOPE DE VEGA: APROXIMACIÓN A UN ESTADO DE LA CUESTIÓN ${ }^{1}$
}

\author{
RELATIONSHIP BETWEEN TIRSO DE MOLINA AND LOPE DE \\ VEGA: AN APPROACH TO THE LITERATURE REVIEW
}

\author{
Alejandro Loeza Zaldivar
}

\begin{abstract}
RESUMEN
En el presente artículo se realiza una cronología de la relación que mantuvo Tirso de Molina y Lope de Vega. A través de una cronología de obras, y las valoraciones críticas de destacados tirsistas, se pone de relevancia los motivos por las cuales dicha relación sigue siendo una interpretación basada en circunstancias. Luego entonces, se plantea una revisión a dicha relación a través de las obras, dedicatorias, laudatorias de los dos escritores.

Palabras clave: Siglo de Oro, Tirso de Molina, Lope de Vega, Arte nuevo, relación escritores áureos.
\end{abstract}

\begin{abstract}
This paper presents a chronology of the relationship between Tirso de Molina and Lope de Vega. The reasons and factors under which this relationship is still an interpretation based on circumstances is through the chronology of their works and the critical analysis of leading tirsistas. This paper is a review of that relationship through the works, dedications, laudatory of writers.

Key words: Golden Age, Tirso de Molina, Lope de Vega, Arte nuevo, relationship between writers.
\end{abstract}

\section{Introducción}

A propósito de la literatura del Siglo de Oro, han sido estudiadas y referidas en numerosas ediciones críticas las diversas problemáticas que enfrentaron a poetas como Francisco de Quevedo con Luis Góngora, ${ }^{2}$ o la relación (no del todo clara) entre Miguel de Cervantes y Lope de Vega (1562-1635), por mencionar algunos ejemplos. En cambio, Gabriel Téllez (1579-1648) se

Dr. Alejandro de Jesús Loeza Zaldívar. Posdoctorado en CEPHCIS-UNAM. Universidad Nacional Autónoma de México. México.

Correo electrónico: literalmente1984@hotmail.com

Recepción: 13- 06- 2017

Aceptación: 31- 07- 2017 
mantuvo al margen de ataques personales a los escritores y dedicó sus comentarios a destacar los rasgos positivos de las obras de sus contemporáneos. Si acaso, la única "broma" que gasta Tirso de Molina, es dedicada al famoso Juan Ruiz de Alarcón, poeta que sufrió burlas de otros autores del Siglo de Oro, relativos a sus defectos físicos. ${ }^{3}$ Otras relaciones, como la de Tirso con Cervantes han sido estudiadas, con diversas valoraciones críticas:

\footnotetext{
Dada la tirantez existente entre Cervantes y Tirso durante la época de la aparición de las Novelas ejemplares, parece razonable pensar en una especie de desafío literario. Cuando aún estaban presentes los lances novelescos de los personajes cervantinos, Tirso se apresura a ofrecer los mismos lances dramatizados para que el público juzgue y sentencie la diferencia categoría artística (García Martín, 1980, pp. 178-179)
}

Así, encontramos diferentes valoraciones e interpretaciones de las relaciones que Tirso mantuvo con los escritores de su época. Entre las relaciones que mantuvo Tirso de Molina, destaca la que tuvo con Lope de Vega. La crítica entorno a la obra de los dos ingenios no es homogéneo con respecto a si, entre Tirso y Lope, había una buena relación o no. Por ejemplo, José M. Oltra asegura que Tirso era "discípulo y defensor" (1985, p. 127) de Lope, mientras que Luis Vázquez afirma que, aunque Tirso sentía respeto por Lope, este le era contrario en estilo: "amor, envidia y honor entran en juego en la novela tirsiana como en su teatro, con la originalidad de que no suele haber venganzas de honor sangrientas, como es el caso en Lope y demás dramaturgos del momento" (Vázquez en Tirso de Molina, 1994, p. 54).

En su elaborado estudio sobre las relaciones de Tirso con autores de su época, R. L. Kennedy apunta que el mercedario y Lope habrían estado enemistados por diversos factores, pero considera relevante el dictamen de 1625 de la Junta de Reformación que le expulsa de Madrid y le prohíbe seguir escribiendo, causada y alentada por el mismo Lope, según la crítica norteamericana (Studies, 1942b, pp. 91-115). De esta forma, encontramos que el estado de la cuestión de las valoraciones críticas de la relación Tirso-Lope suelen entender una enemistad entre los dramaturgos. Por ello, en el presente trabajo recogemos los elementos que el grueso de esta crítica a consensado como ataques y/o críticas mutuas, para valorar la relación TirsoLope. A partir de una cronología de obras publicadas y representadas, veremos cómo se desarrolla esta relación a partir de dedicatorias en las obras y lo referente a Jerónima de Burgos y su actuación en la obra de Tirso de Molina, Don Gil de las Calzas Verdes.

\section{Cronología de una relación entre Tirso y Lope}

La obra de Lope de Vega supuso un paradigma en las letras áureas, particularmente en lo que se refiere a la comedia, género que reformaría con su famosa Arte nuevo de hacer comedias (1609). Tirso admira la obra de Lope, y lo demuestra con palabras en dedicatorias, preliminares y en voz de personajes dentro de sus comedias, a la vez que sigue estilísticamente el Arte nuevo. Tal fue este seguimiento que la Primera parte de las comedias de Tirso de Molina fueron confundidas con obras de Lope, aunque dicha confusión tenga otras circunstancias más específicas. ${ }^{4}$ Sin embargo, las palabras que devolvería Lope son mucho más esquivas y dedicaría, apenas, las palabras justas a la obra de Tirso. Pero, miremos a detalle las referencias hechas dentro de las obras de los autores.

\subsection{Dedicatorias y referencias en obras}

Una de las primeras referencias de admiración de Tirso por la obra de Lope la encontramos en la comedia El vergonzoso en palacio (1611) donde dice el mercedario apoyar a Lope 
para ofrecer su punto de vista sobre el modelo y la libertad creadora del poeta y para extender su crítica a los malos actores, que en más de una ocasión arruinaron sus obras... la conversación termina con la defensa y alabanza explícitas de Lope y la declaración tirsiana de ser su discípulo (Oteiza en Tirso de Molina, 2012a, pp. 156-157)

En Como han de ser los amigos (1612), utiliza la métrica de los tercetos encadenados pues "Son los tercetos para cosas graves" (Rozas, 1976, p. 232) en claro seguimiento a lo dictado por Lope. Otra referencia al Arte nuevo está en los siguientes versos del auto sacramental No le arriendo la ganancia (1613):

Desabrimiento.

Hermosa es.

Envidia.

La variedad

siempre tuvo buena cara. (Tirso de Molina, 1998, Autos

sacramentales I, vv. 692-3)

Y por su parte, Lope escribió: "aquesta variedad deleita mucho; / buen ejemplo nos da la naturaleza" (2011, vv. 178-179). En este sentido y sobre el seguimiento de Tirso al Arte nuevo, ha valorado Rull la obra de Tirso como una "emulación fallida" de la obra de Lope con respecto al auto sacramental Los hermanos parecidos (1615), calificándolo de: "mero continuador de Lope, sin sus cualidades y con sus defectos" (1986, p. 75). Por su parte, Canonica apunta que Tirso usó un tono irónico en contra de Lope en la comedia El amor médico ${ }^{5}$ de 1620. En El amor médico ha visto Blanca de los Ríos en su edición de 1958 a la obra, y posteriormente Canonica (1998, pp. 388-392) una crítica a los "sacrílegos" amores de Lope, a partir de la hipótesis de que Tirso toma los nombres de la comedia La portuguesa y dicha del forastero del Fénix, a saber: Micaela, Jerónima y Marta, que en la obra de Tirso serían Micaela Luján, Jerónima de Burgos y Marta de Nevares. Por su parte Blanca de los Ríos afirma: "hiciéronse públicos los sacrílegos amores del Fénix con Amarilis (Doña Marta de Nevares)... Aquí, en El amor médico,... no pudo reprimir sus indignadas burlas contra los amoríos de Lope y Doña Marta” (de los Ríos en Tirso de Molina, 1958, pp. 965-966).

Así, de los Ríos en su estudio al Amor médico, va subrayando "flechazos satíricos" en contra de Lope de Vega, con el sustento de los nombres (coplas, quizás de carácter burlesco). Por si fuese poco, la misma de los Ríos (1958, v. 1385) vio en estos versos una crítica al sacerdocio del Fénix: “Para qué se llama cura / si es la misma enfermedad?” (1958, vv. 14991500), aunque Jammes, editor de Letrillas de Góngora, afirmó que no hay “alusión maldiciente a Lope de Vega" (1967, p. 98).

Por su parte, en La villana de Vallecas (1620) de Tirso de Molina, el personaje Gabriel da noticias de la corte y Madrid al indiano Pedro, a quien también le referirá las circunstancias del teatro y dedica los siguientes versos a la obra de Lope de Vega:

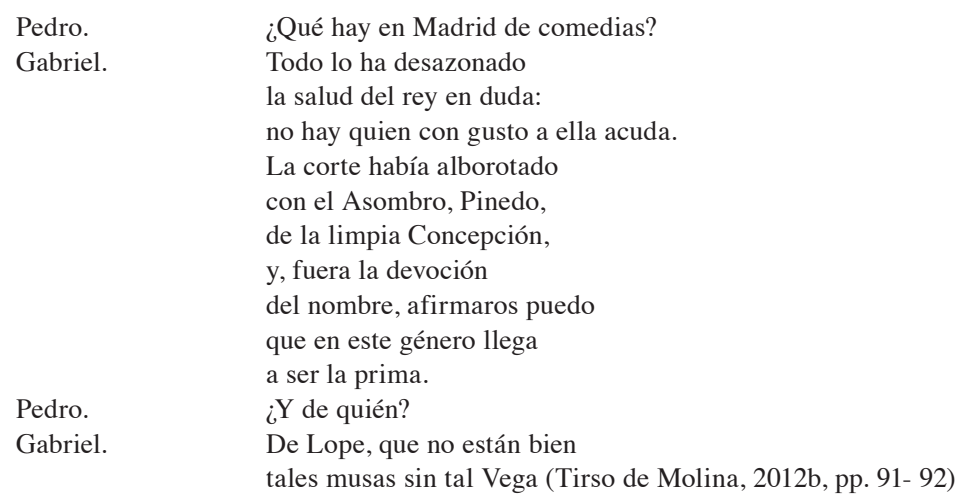


La comedia a la que se refieren los personajes es La limpieza no manchada, de Lope, representada el 29 de octubre de 1618 por la compañía de Baltasar de Pinedo en la Universidad de Salamanca con motivo del juramento del nuevo estatuto, según el cual todos los graduados se comprometen a defender la pura y limpia concepción de la Virgen María. En ese mismo tópico, Tirso de Molina elabora unos versos finales en La villana de Vallecas, los cuales son un elogio que hace Tirso a Lope, en clara alusión a lo que, para la segunda década del siglo XVII, era por todos sabido: el triunfo que tenían las comedias de Lope de Vega en los teatros de corrales. Esta comedia, según explica S. Eiroa (en Tirso de Molina, 2011b, p. 58) en su introducción a dicha comedia, Tirso de Molina redactó La villana de Vallecas a partir del canon de Lope de Vega, plasmado en su Arte nuevo. Así, por ejemplo, el desenlace de $L a$ villana de Vallecas (vv. 3898-3965) rompe con el esquema rítmico sugerido por el Arte nuevo, por ser un final "rápido". Otras características de la obra de Lope sí que las encontramos, como la unidad de acción propuesta en el Arte nuevo, sobre las acciones del personaje principal:

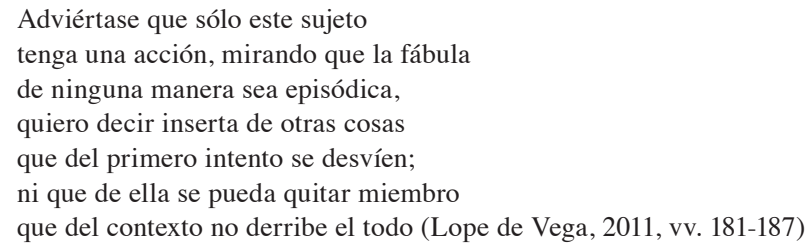

En 1620, Lope de Vega dedicó al mercedario su obra Lo fingido verdadero, indicando que conocía las "historias divinas" que había puesto en escena y le reconoce lo que "a todos nos enseña”. Pero los elogios por parte del Fénix no cesan. En la XVI Parte de su teatro (1621) Lope le dedica las siguientes palabras a Tirso:

\begin{abstract}
Al R. P. Presentado F. Gabriel Téllez, religioso de nuestra Señora de la Merced, redención de cautivos.Entre los estudios de las sagradas letras también ha lucido en V. P. el de las humanas, de que tenemos claros ejemplos, y para descansar el arco, tal vez el de las musas. Algunas historias divinas he visto de V. P. en este género de poesía, por las cuales vine en conocimiento de su fertilísimo ingenio, pues a cualquiera cosa que le aplica, le halla dispuesto, y con la afición que desta correspondencia nace, aunque a los envidiosos parezca imposible simpatía, quedé cuidadoso de ofrecerle alguna, y por ventura, en reconocimiento de lo que a todos nos enseña (en Tirso de Molina, 1994, p. 17)
\end{abstract}

Esta cuidada dedicatoria es mesurada y correcta: no agrega ni desconoce el ingenio de Tirso de Molina, que no podía dejar indiferente a Lope. Explica Blanca de los Ríos (en Tirso de Molina, 1958, p. 967) que Menéndez Pelayo calificó esta dedicatoria como "cautelosa", ya que veía en Tirso un potencial rival en el teatro.

En el sentido señalado por Menéndez Pelayo es notable que en el metafórico "Jardín de los poetas" de La Filomena (1621), los personajes hablan de los poetas más famosos y reconocidos de Madrid por aquellos años, sin embargo, nada dirá Lope de Tirso, cuando dentro de la obra se celebra a dramaturgos menores, como Salucio del Poyo (1530?-1614?). Sin embargo, en ese mismo año, Tirso dedica palabras de admiración a Lope, en La fingida Arcadia:

$\begin{array}{ll}\text { Ángela. } & \text { Pluma de Lope de Vega } \\ & \text { la fama se deja atrás. } \\ \text { Lucrecia. } & \text { ¡Prodigioso hombre! ¡No sé } \\ & \text { qué diera por conocerle! } \\ & \text { A España fuera por verle, } \\ & \text { si a ver a Salomón fue } \\ & \text { la celebrada etiopisa. } \\ \text { Ángela. } & \text { Compara con proporción } \\ & \text { que no es Lope, Salomón }(1989, \text { vv. 17-25) }\end{array}$


Sin embargo, Canonica ve en otras partes de esta misma comedia, elementos irónicos que ya dejaban entrever el malestar del fraile por lo de La Filomena y las Justas de San Isidro, que premiaron incluso, a una niña de cinco años: Antonia de Nevares. Las claves de esta interpretación las va encontrando en diversos pasajes que refieren a la envidia. Quizás, como apunta Canonica (1998, p. 33), Tirso estaría cansado de alabar la obra de Lope sin que este prestara atención a su obra. En lo sucesivo, el mismo crítico explica (1998, pp. 34-35) cómo ese silencio sobre Tirso tenía también motivos políticos pues: "Lope retrasó voluntariamente la publicación de la comedia dedicada a Tirso (Lo fingido verdadero) en la Parte XVI para poder dedicar ésta al nuevo hombre fuerte, el conde-duque de Olivares, notorio enemigo de Tirso". Está claro que, durante aquellos años de efervescencia teatral, Tirso de Molina se deja la pluma en alabanzas a Lope de Vega, quien contesta, cuando menos, de una manera más mesurada y menos festiva. Esa disparidad no pudo haber dejado indiferente al mercedario.

En los Cigarrales de Toledo (1622) Tirso defiende el modo de hacer teatro de Lope, en su dedicatoria al Fénix, a quien ubica dentro del Parnaso, alabando su "lira", semejante a otro grande de las letras áureas, como Garcilaso de la Vega. En estas décimas laudatorias, dice Tirso de Lope:

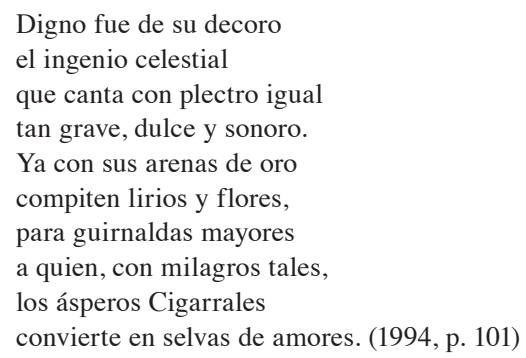

Más adelante analizamos el Cigarral cuarto, relativo a Jerónima de Burgos y la problemática que le valió con Lope, pero sirva esta dedicatoria de los Cigarrales para demostrar la admiración y buena estima que tenía Tirso por Lope de Vega hasta 1622. Aunque, como hemos argumentado, esa admiración comenzaba a fracturarse.

En la Justa poética en honor a San Isidro Labrador (1622), en las que el mercedario participó con octavas reales y décimas, este no fue premiado ni alcanzó mención alguna entre los laureados poetas que eran menores al propio Tirso de Molina. Sin embargo, trascendió que Lope de Vega era juez en dichas justas poéticas, lo cual no parecía tener relación con las dedicatorias que había hecho anteriormente al ingenio de Tirso.

La crítica cree que la comedia Antona García fue escrita entre 1622 y 1625, años claves en las relaciones entre Tirso y Lope. Críticos como Kennedy (1983), datan la composición de esta obra entre 1621 y 1622 porque las alabanzas que Tirso había vertido en La fingida Arcadia (1621) no obtuvieron respuesta de Lope y, como hemos visto, al año siguiente su participación no fue ni siquiera premiada ni comentada por el mismo Lope. Por lo tanto, Tirso introduce un tema que, si bien ya había utilizado, en Antona García se perfila con sutil interpretación, dado el contexto mencionado. Los versos que probablemente harían referencia a dicha "envidia insana" por parte de Lope hacia Tirso son los siguientes:

$\begin{array}{lll}\text { Portugués 3. } & \text { ¿Y vos qué mercaduría } & \\ \text { Castellano 7. } & \text { ¿Yondéis? Envidia. } & \\ \text { Portugués 3. } & & \\ \text { Castellano 7. } & \text { todo mi caudal he puesto. } & \\ \text { Portugués } 4 . & \text { Buen caudal, por vida mía. } & \end{array}$


$\begin{array}{ll}\text { Castellano 7. } & \begin{array}{l}\text { Bueno o malo, ya le gasta } \\ \text { gente que os admiraréis. }\end{array} \\ \text { Portugués 4. } & \text { Vos alabarle podéis, } \\ & \text { pero no es de buena casta. } \\ \text { Castellano 7. } & \text { Pues véndese agora tanta } \\ & \text { envidia a ingenios diverso } \\ & \text { que hay hombre que haciendo versos } \\ & \text { a los demás se adelanta, } \\ & \text { y aunque más fama le den, } \\ & \text { es tal, la verdad os digo, } \\ & \text { que quita el habla a su amigo } \\ & \text { cada vez que escribe bien. } \\ & \text { ¡Maldiga Dios tal bajeza! (Tirso de Molina, 1999, vv. 2122-2138) }\end{array}$

El diálogo construido por Castellano 7 es una referencia a la ingratitud de los ingenios a la construcción de las laudatorias y con el respectivo cierre de maldecir tal bajeza y la de premiar ingenios menores. Sería difícil no entender la construcción de estos versos a propósito de las circunstancias que rodeaban para esos años las dedicatorias y las justas poéticas en las que se encontraban Lope y Tirso. Sin embargo, en la misma obra y más adelante, se hace una referencia a los parámetros que Tirso seguía del Arte nuevo, y de que, cuando el mercedario escribe, lo hace sin pretender "morder" a nadie:

$\begin{array}{ll}\text { Portugués 3. } 3 . & \text { ¿Satirizáis? } \\ \text { Castellano 7. } & \text { No se hallará que presuma } \\ & \text { de mí, que muerda mi pluma } \\ & \text { a nadie; antes, si miráis } \\ & \text { lo que he impreso y lo que he escrito, } \\ & \text { por modo y estilo nuevo } \\ & \text { solemnizo a quien no debo } \\ & \text { buenas obras (Tirso de Molina, 1999, vv. 2146-2153) }\end{array}$

Una forma de admitir la renovación de Lope, pero que en el estilo despega del maestro. Finalmente, en la obra se refiere a la humildad entre poetas, y el absurdo que supone las envidias o críticas que entre ellos se dan. Sin embargo, en estos versos Tirso parece explicar cómo la indiferencia puede significar envidia:

Castellano 7.

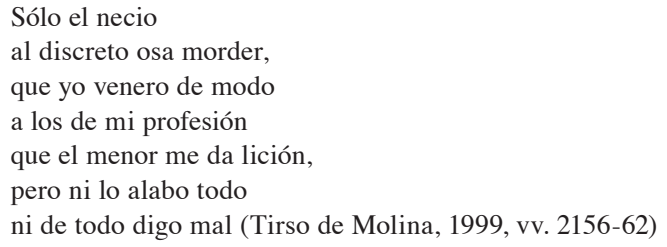

Sobre esta misma comedia y los versos ya citados, Blanca de los Ríos añade que Tirso estaba molesto con Lope ya que, en 1622 sus Justas Isidorianas no obtuvieron ni premio ni mención alguna por el que fuese juez: Lope de Vega. Y agrega "El enojo procedía... de la injusta exclusión que el Fénix hizo de Tirso de entre los poetas que incluyó en el "Jardín...” de La Filomena (1621)" (en Tirso de Molina, 1958, p. 405).

Pocos años después, en 1625, la Junta de Reformación de las Costumbres, prohibió publicar obras a Tirso de Molina, a la vez que fue expulsado de Castilla. Fue un duro golpe para el mercedario, sobre todo en lo que a la expresión estética le suponía. El caso ha sido estudiado y mencionado por varios biógrafos de fray Gabriel Téllez, con diversos motivos por los cuales se dictó esta determinación, que van desde motivos morales-religiosos, hasta políticos y, por 
supuesto, envidias de un escritor famoso. En la relectura que hace Kennedy sobre el tema (1983, pp. 137-138), encuentra en los siguientes versos de Antona García una posible referencia a la "traición" que Lope le habría propinado al mercedario y, que a su salida de Madrid, en su camino a Toro, en la venta de Mollorido, habría introducido estos diálogos entre el castellano y los portugueses. Si bien la redacción de Antona García estaba finalizada en 1621, los críticos creen que en 1625 la retoma e introduce dichos versos, pues, como he expuesto, unos diálogos se prestan al tema de la envidia y celo entre poetas y escritores, además de los malos agradecimientos. No obstante, es importante mirar con cautela la citada Kennedy, ya que los datos son de difícil comprobación. Galar en su Introducción a esta comedia, afirma que

parece claro que Tirso culpa de su apresurada salida de Madrid a dos individuos: a un necio y acomodado personaje sin
talento para las letras, que bien podría ser Antonio Hurtado de Mendoza (vv. 2024-41), y al mejor y más famoso poeta
que ha caído en la envidia insana (vv. 2122-53), que no puede ser otro que Lope de Vega (en Tirso de Molina, 1999, p. 491)

Según explica Vásquez (en Tirso de Molina, 1994), dichas omisiones por parte de Lope de Vega, generaron en el mercedario un malestar que se plasmó en Antona García, que el propio crítico reconoce haber consultado de la obra de Ruth L. Kennedy que refiere dicha relación en su artículo «On the date of five plays by Tirso» y publicadas en Hispanic Review 10, en 1942. Por ello, los sucesivos críticos encontrarán una "socarrona ironía” en las alabanzas que hace Tirso de la obra de Lope, después de 1622. Dicha interpretación está respaldada en las claves proporcionadas por Blanca de los Ríos y la ya mencionada Kennedy. Siguiendo esta línea, Vásquez interpreta que:

A veces, como en La fingida Arcadia, le bastará a Tirso cambiar una sola palabra de un soneto lopiano para que el público entienda. Lope había escrito: «la toma de la misma injusta mano». Tirso modifica: «la toma de la misma ingrata mano», aludiendo a la mano misma de Lope. Sí, ha sido ingrata la mano del Fénix para con Tirso, su más economiasta defensor (en Tirso de Molina, 1994, p. 486)

Tirso era conocedor de la importancia de la obra de Lope, pues le reconoce "a la Vega de España" su "arte nueva de hacer comedias", por la influencia temática y la originalidad de sus comedias. Sin embargo, apunta Vásquez que, la obra de Tirso adquirió tal calidad, que Lope llegó a "picarse y reducirá sus elogios al Mercedario a lo mínimo inevitable, cuando prodiga alabanzas a comediógrafos y poetas apenas dignos de figurar en el Laurel de Apolo" (en Tirso de Molina, 1994, p. 485).

Pasan años antes de que Tirso vuelva a escribir, entre la prohibición generalizada y el estigma particular en su contra. Sin embargo, con los años va preparando hagiografías que intentarían repetir el éxito cosechado en la miscelánea los Cigarrales de Toledo. Además del vacío en el que caía las misceláneas, al no ser ni novela ni teatro, parece que Tirso de Molina trata de reivindicar su obra del estigma de las inmoralidades. Y a la par de sus proyectos hagiográficos, decide pulir sus comedias de corte histórico y sacro, cuando en 1635 se publica Cuarta parte de comedias de Tirso de Molina, y la aprobación corre a cuenta de Lope de Vega, quien dice que dicha obra:

no tiene cosa en que ofenda ni a nuestra Fe ni a las buenas costumbres. Muestra en ellas su autor vivo y sutil ingenio en los conceptos y pensamientos, y en la parte sentencia grave sus estudios en todo género de letras con honestos términos tan bien considerados de su buen juicio (en Tirso de Molina, 1999, p. 58)

De esta escueta y rutinaria aprobación, no desprendemos un particular interés ni admiración hacia Tirso por parte de Lope, y menos aún si lo comparamos con las palabras dedicadas por Pérez de Montalbán al mercedario en la misma obra: 
lo sentencioso de los conceptos admira, lo satírico de las faltas corrige, lo chistoso de los donaires entretiene, lo enmarañado de la disposición deleita, lo gustoso de las cadencias enamora y lo político de los consejos persuade y avisa, siendo su variedad discreta como un ramillete de flores diferentes que, además de la belleza y la fragancia, aficiona con la diversidad y la compostura. Si fuera lugar de alabanzas, muchas se me ofrecían del autor, maestro por su gran talento en las sagradas letras, y Apolo, por su buen gusto, de las curiosas Musas; y así me contentaré con asegurar que merece no la licencia que pide que imprimir esta Cuarta parte, sino un género de apremio honroso para obligarle a que de muchas a la imprenta en gracia de la lengua castellana, en honra de Madrid su patria, en gusto de los bien intencionados y pesadumbre de los maldicientes (en Tirso de Molina, 1999, pp. 55-56)

Como se lee, Juan Pérez Montalbán, amigo de Tirso, primero despeja toda duda de la alta calidad moral y aleccionadora de las obras del escritor. Posteriormente lo consagra a la mayor altura de la expresión poética entre el parnaso, para finalmente, denotar a los "maldicientes", es decir, a los envidiosos de Tirso de Molina. Una singularidad que, en los preliminares a la misma obra, dos posturas, la del amigo y el probable "maldiciente" se encuentren entre letras. Sin embargo, aún estaba por escribirse más capítulos en la relación entre Tirso de Molina y Lope de Vega.

\title{
2.2 Don Gil de las Calzas Verdes, Los Cigarrales de Toledo y la carta de Lope de Vega
}

No obstante todas las dedicatorias y referencias posibles dentro de la obra de Tirso y Lope, conocemos un hecho que está mejor documentado y que hemos preferido tratar en un apartado distinto, ya que es crucial para entender el distanciamiento y probable enemistad de Lope de Vega hacia Tirso de Molina. A saber, en 1615 la comedia Don Gil de las Calzas Verdes es representada en Toledo, y la crítica coincide en que Lope de Vega acudió como espectador a la representación de dicha obra. En dicha comedia, ocupó el papel principal la actriz Jerónima de Burgos, quien fuese amante de Lope de Vega. Si observamos la cronología anterior, Lope ya había dedicado palabras a Tirso. Pero, en 1621 se publica Los Cigarrales de Toledo, novela miscelánea en la cual, como hemos visto, Tirso dedica palabras al Arte nuevo. Sin embargo, en el Cigarral cuarto, el comediógrafo aprovecha para excusar algunos malos resultados en las comedias, en voz del ficticio Melchor, las malas y/o desatinadas interpretaciones de los actores, además de un físico contrario a lo esperado:

\begin{abstract}
La segunda causa (prosiguió don Melchor) de perderse una comedia, es por lo mal que le entalla el papel al representante. ¿Quién ha de sufrir, por extremada que sea, ver que habiéndose su dueño desvelado en pintar una dama hermosa, muchacha y con tan gallardo talle que, vestida de hombre, persuada y enamore la más melindrosa dama de la corte, salga a hacer esta figura una del infierno, con más carnes que un antruejo, más años que un solar de la Montaña, y más arrugas que una carga de repollos, y que se enamore la otra y le diga: “¡ay, que don Gilito de perlas!, ¡es un brinco, un dix, un juguete del amor!”? (Tirso de Molina, 1994, pp. 452-453)
\end{abstract}

Este apartado es alusión a la representación de Don Gil de las Calzas Verdes (1615) y del papel que hizo Jerónima de Burgos en dicha comedia, a quien, como se puede leer, la acusa de ser gorda y vieja en un papel hecho para una actriz joven, esbelta y guapa. El comentario, no habría sido del agrado de Lope de Vega, ya que, por su epistolario, sabemos que la actriz era amante del Fénix. Entre el éxito que suscitaran las comedias de Tirso, y la opinión de este sobre la amante, se cree que "el Fénix siempre llevó mal el éxito del Tirso comediógrafo" (en Tirso de Molina, 1999, p. 58). Aunado al celo profesional que pudiese existir de Lope hacia Tirso, el "desprecio" que tenía Lope de Vega por la obra Don Gil de las Calzas Verdes, queda asentado en carta personal remitida al duque de Sessa (el 25 de junio de 1615), donde califica dicha obra "con tantos donayres, vozes y desatinos que se llegaba más auditorio que ahora tienen con Don Gil de las calzas verdes, desatinada comedia del Mercenario" (en González de Amezúa, 1941, p. 206). 
Por su parte, Blanca de los Ríos (en Tirso de Molina 1958, pp. 883-885) señala que en Quien no cae no se levanta (1628) de Tirso, los siguientes versos refieren nuevamente a Jerónima de Burgos, quien por esos años habría tomado el hábito de monja:

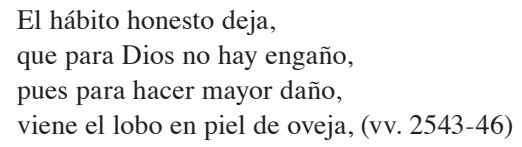

Otros han reforzado la hipótesis de Blanca de los Ríos (por ejemplo Maurel, 1971, p. 284) que de manera bastante argumentada, parece exponer la crítica a la amante de Lope de Vega como el motor de su antipatía. De manera posterior y con los años Tirso habría entendido que dicha crítica le valió el desprecio del poeta, Tirso comienza una sutil crítica no solo (como se ha visto) a la toma de hábitos de Jerónima, sino también a la vida libertina de Lope, sobre todo cuando este, en los últimos años de su vida, abrazó el sacerdocio pese a vivir en concubinato.

El año de 1635 fue un cierre de ciclo en la obra de Tirso, pues en dicho año publica la Cuarta parte de comedias y el Deleitar aprovechando, novela miscelánea que lo llevaría a retomar las hagiografías y a ir abandonando las comedias. Después de estas publicaciones, a Tirso solo le quedaría la redacción y publicación de una última comedia más: Las quinas de Portugal de 1638. Además de dicha comedia, Tirso dedicó los últimos años de su vida a la redacción de la Historia de la orden de la merced. Por su parte, Lope de Vega fallece en 1635, siendo esa perene dedicatoria en la Cuarta parte de comedias, las últimas palabras hechas por el Fénix hacia Tirso, quien vivió hasta 1648. Es interesante el silencio que guardó Tirso de Molina después de la muerte del Fénix, sin volver a mencionarlo en sus obras y escritos, sin valoración o interpretación sobre la misma. Esta es la cronología de versos, dedicatorias, preliminares, laudatorias y cartas que son, explícita o implícitamente, una referencia a la labor entre ambos comediógrafos del Siglo de Oro y su relación.

\section{Conclusiones}

Si bien, es posible que Tirso mantuviese una relación en general buena con todos los escritores de su época, ${ }^{6}$ con Lope de Vega mantuvo, al menos, una tensión que hasta antes de 1625, fueron sólo encomios. No encontramos en lo hasta hoy conocido de las obras y escritos del fraile mercedario texto que explicite ese posterior "desencanto" con Lope, pero es perceptible un alejamiento, tanto de la comedia como de las alabanzas a la obra del Fénix. Es claro que Tirso, después de la prohibición de 1625 de seguir escribiendo, recibe un duro golpe que le irá llevando, cada vez más, a retomar las hagiografías y abandonar la comedia. En ese mismo tránsito, cesan sus alabanzas al Fénix.

Por una parte, es clara la valoración de Lope hacia Tirso, pero no así las acciones y el alcance que tuvieron estas en las decisiones de la Junta de Reformación, así como posibles ataques y bloqueos editoriales y en los tablados que el Fénix le habría procurado al mercedario. Tirso, mucho más discreto, al menos en el papel, no deja saber con total certeza si esos "dardos" serían dirigidos al insigne dramaturgo español o se trataría de una crítica más general. Sabemos, en conceso, de la admiración y práctica que hizo el mercedario (como casi todos los dramaturgos de su época) del Arte nuevo, pero también es clara la ausencia de palabras y referencias al Fénix, conforme Tirso va alejándose de los tablados. 
Las explícitas menciones del mercedario a Lope nunca dejan de ser de admiración y laureles por su talento y la clara relevancia que tuvo dentro de las letras áureas. Incluso hay quien afirma que:

La influencia del Fénix no se limita a la doctrina y a la teoría de la nueva comedia; también le debe Tirso cierto número de trazas, de episodios, de caracteres y de reminiscencias dentro los más interesantes de sus propias creaciones (Ciorenescu, 1971, p. 152)

Si en el aspecto personal Lope estaba enfrentado a Tirso, en el estilo comulgaban, aunque los temas y manejos fuesen distintos. Si Lope llegó a sentir esos celos que antes hemos comentado o temor por el favor del púbico es un tema que con el material actual no es posible aseverar. No obstante, podemos afirmar que Tirso sigue y predica el Arte nuevo, Lope lo sabe y no puede ser indiferente al ingenio y éxito de las comedias de Tirso. El asunto de Jerónima de Burgos le hace escribir la referida carta en la que muestra visceralidad por el mercedario. Fray Gabriel Téllez dedica décimas y referencias a Lope y este es indiferente o al menos "correcto" en sus respuestas y luego, el silencio.

Son estas las referencias cruzadas y que son susceptibles (como la crítica acá expuesta lo demuestra) de entender como ataques e injurias entre estos dos comediógrafos. Con ello queda de manifiesto, una vez más, el ingenio de Tirso y Lope quienes se mantuvieron esquivos a decir de forma abierta sus inquietudes o discrepancias. Por lo tanto, utilizaron sus obras para evitar abiertas palabras, escondiendo detrás de los versos lo que quizás fue una relación menos fortuita de lo que hasta ahora conocemos y podemos sustentar en el material que nos han legado.

Es conclusión del presente artículo que Tirso de Molina sentía profunda admiración por la obra de Lope de Vega y no cuestionaba ni sus directrices plasmadas en el Arte nuevo ni en los tópicos de sus comedias. Sin embargo, Lope de Vega, receloso de la fama y fortuna alcanzada por su obra, no habría visto sin cierta inquietud cómo se celebraba favorablemente la obra del mercedario. No obstante, no habría encontrado cosa alguna que criticarle a sus obras: correctas en los temas, profundas en su sentido y estructuralmente le seguían a él, el Fénix de los ingenios. Pero no cabe duda que, sumado al recelo profesional por ganar el favor del público y los mecenas de la corte, para Lope de Vega era imperdonable la crítica, primero, a su amante y segundo, a su forma de vida, alejada de la rectitud moral de Tirso de Molina. Ante la falta de agradecimiento y correspondencia por parte de Lope, Tirso se aleja y nota que la vida de Jerónima y el Fénix ofende su propia forma de vida. El silencio de los últimos años es manifestación de una enemistad circunstancial pero, y pese a ella, no cabe duda de que ambos sabían reconocer el talento y la labor del otro.

\section{Notas}

1. Este artículo fue elaborado gracias al otorgamiento de la beca postdoctoral del programa de la UNAM, que desarrollo actualmente en el CEPHCIS-UNAM, en Mérida, Yucatán, bajo la dirección de la Dra. Carolina Depetris.

2. Para ver la famosa enemistad entre estos dos escritores remito a la siguiente bibliografía, aunque el tema ha sido ricamente abordado por infinidad de artículos: Acereda, A., "Motivos burlescos en las sátiras de Quevedo contra Góngora", en Selected Proceedings of the Pennsylvania Foreign Language Conference (1991-1992), ed. Martín, G. C., Pittsburgh, Dept. Of Modern Langs., Duquesne Univer-sity, 1995, pp. 7-15; Conde Parrado, P. and J. García Rodríguez, "Entre voces y ecos: Quevedo contra Góngora (una vez más)”, Edad de Oro, 24, 2005, pp. 107-144; González Martínez, L., "Góngora según Quevedo: breve relación de una historia injuriosa", Scriptura, 5, pp. 1989, 17-30.

3. Casi todos relativos a su joroba. Ver la introducción que hace Castro Leal a Ruiz de Alarcón, J. (1961). Cuatro comedias. Castro Leal, A (Ed.). México: Porrúa. 
4. Los detalles y circunstancias de dicha atribución se pueden encontrar en la edición de Primera parte de comedias de Tirso de Molina, editada por Ignacio Arellano en 2011.

5. La referencia completa a esta interpretación se encuentra en Canonica (1990, pp. 375-407).

6. R. L. Kennedy (1974) realizó un extenso estudio de dichas relaciones, en las que encuentra rivalidad entre el mercedario y Antonio Hurtado de Mendoza, Luis Vélez y Juan Ruiz de Alarcón, además del propio Lope de Vega. Kennedy sustenta esto en el proceso que le realizó la Junta de Reformación.

\section{Bibliografía}

Acereda, A. (1995). Motivos burlescos en las sátiras de Quevedo contra Góngora. En G. C. Martín (Ed.). Selected Proceedings of the Pennsylvania Foreign Language Conference (1991-1992). (pp. 7-15). G. C., Pittsburgh: Dept. Of Modern Langs, Duquesne University.

Canonica, E. (1990). Tirso contra Lope: imitación irónica de La portuguesa y dicha del forastero en El amor médico. Revista de Literatura. 52 (104), 375 -407.

Canonica, E. (1998). La fingida Arcadia: desde su fuente lopesca hasta su desembocadura calderoniana. En I. Arellano, B. Oteiza y M. Zugasti (Eds.). El ingenio cómico de Tirso de Molina, Actas del Congreso Internacional Pamplona, Universidad de Navarra, 27-29 de abril de 1998. (pp. 33-45). Madrid-Pamplona: GRISO (Universidad de Navarra)-Revista Estudios, 1998.

Cioranescu, A. (1971). Tirso de Molina y Lope. En A. D. Kossoff y J. Amor y Vázquez (Eds.). Homenaje a William L Fichter. (pp. 48-106). Madrid: Editorial Castalia.

Conde Parrado, P. y García Rodríguez, J. (2005). Entre voces y ecos: Quevedo contra Góngora (una vez más). Edad de Oro. 24, 107-144.

Florit, F. (1986). Tirso de Molina ante la comedia nueva. Estudios. 155, 1-186.

Florit, F. (2000). Lope de Vega y Tirso de Molina en 1621: la dedicatoria de Lo fingido verdadero. En M. G. Profeti (Ed.). Otro Lope no ha de haber (Atti del Conve-gno Internazionale su Lope de Vega, 10-13 febbraio, 1999). (pp. 85-96). Firenze: Alinea Edictrice.

González de Amezúa, A. (1941). Epistolario de Lope de Vega. Madrid: Real Academia Española.

García Martín, M. (1980). Cervantes y la comedia española en el siglo XVII. Salamanca: Universidad.

González Martínez, L. (1989). Góngora según Quevedo: breve relación de una historia injuriosa. Scriptura. 5, 17-30.

Jammes, R. (1967). Études sur l'oeuvre poétique de don Luis de Góngora y Argote. Burdeos: Féret.

Kennedy, R. L. (1942a). On the date of five plays by Tirso. Hispanic Review. 10, 183-214.

Kennedy, R. L. (1942b). Certain phases of the sumptuary decrees of 1623 an their relation to Tirso`s Theatre. Hispanic Review. 10, 91-115.

Kennedy, R. L. (1974). Studies in Tirso, I: The Dramastist and his Competitors, 1620-26. Portland: North Carolina Studies in the Romance Languages and Literatures.

Kennedy, R. L. (1983). Estudios sobre Tirso I. El dramaturgo y sus competidores (1620-1626). Estudios. 140-141, 7-302. 
Lope de Vega, F. (1982). La Gatomaquia. C. S. de Cortázar (Ed.). Madrid: Castalia.

Lope de Vega, F. (2011). Arte nuevo de hacer comedias. E. Rodríguez (Ed.). Barcelona: Castalia.

Maurel, S. (1971). L' univers dramatique de Tirso de Molina. Poitiers: Université.

Oltra, J. M. (1985). La miscelánea en Deleytar aprovechando. Reflejo de una coyuntura tirsiana. Criticón. 30, 127-150.

Rozas, J. M. (1976). Significado y doctrina del “Arte nuevo” de Lope de Vega. Madrid: SGEL.

Ruiz de Alarcón, J. (1961). Cuatro comedias. A. Castro Leal (Ed.). México: Porrúa.

Rull, E. (Ed). (1986). Autos sacramentales del Siglo de Oro. Barcelona: Plaza y Janés.

Tirso de Molina. (1958). Obras dramáticas completas. Vol. III. B. de los Ríos (Ed.). Madrid: Aguilar.

Tirso de Molina. (1989). El mayor desengaño; La fingida Arcadia. B. de los Ríos (Ed.). Madrid: Aguilar.

Tirso de Molina. (1994). Cigarrales de Toledo. L. Vázquez (Ed.). Madrid: Castalia.

Tirso de Molina. (1998). Obras completas. Autos sacramentales I. El colmenero divino, Los hermanos parecidos, No le arriendo la ganancia. I. Arellano, B. Oteiza y M. Zugasti (Eds.). Pamplona: IET.

Tirso de Molina. (1999). Obras completas. Cuarta parte de comedias I. I. Arellano (Ed.). Pamplona: IET.

Tirso de Molina. (2003). Obras completas. Cuarta parte de comedias II. I. Arellano (Ed.). Pamplona: IET.

Tirso de Molina. (2011a). Obras Completas Volumen I. Primera parte de Comedias. Palabras y plumas, El pretendiente al revés. El árbol de mejor fruto. I. Arellano (Ed.). MadridFrankfurt am Main: Iberoamericana-Vervuert.

Tirso de Molina. (2011b). La villana de Vallecas. S. Eiroa (Ed.). Pamplona: IET.

Tirso de Molina. (2012a). El vergonzoso en palacio. B. Oteiza (Ed.). Madrid: Real Academia Española-Barcelona: Galaxia Gutenberg-Círculo de Lectores.

Tirso de Molina. (2012b). Obras Completas Volumen II. Primera parte de Comedias. La villana de Vallecas. El melancólico. El mayor desengaño. I. Arellano (Ed.). MadridFrankfurt am Main: Iberoamericana-Vervuert.

Vázquez Fernández, L. (1988). Tirso de Molina. Diálogos teológicos y otros versos diseminados. Zaragoza: Kassel Edition Reichenberger.

Zamora Lucas, F. (1941). Lope de Vega, censor de libros. Larache: Artes Gráficas Biosca.

Zamora Lucas, F. (1974). Elogios literarios, dedicatorias y aprobaciones de libros de Tirso de Molina y de sus amigos y admiradores. Homenaje a Guillermo Guastavino. (pp. 375-401). Madrid: Asociación Nacional de Archiveros, Bibliotecarios y Arqueólogos.

Zugasti, M. (1995). Sobre la novela histórica de asunto hagiográfico en el Barroco: a propósito de El bandolero de Tirso de Molina. Estudios. 52, 189-190, 367-386. 